\title{
Optimal Conditions for the Enrichment and Isolation of Methanol-assimilating Yeasts
}

\author{
By J. P. VAN DIJKEN AND W. HARDER \\ Department of Microbiology, University of Groningen, \\ Haren (Gr.), The Netherlands
}

(Received 6 March 1974; revised 2I May 1974)

INTRODUCTION

The existence of yeasts capable of utilizing methanol as the only source of carbon and energy for growth has been discovered comparatively recently by studying new isolates and screening culture collections (Ogata, Nishikawa \& Ohsugi, 1969; Asthana, Humphrey \& Moritz, 1971; Sahm \& Wagner, 1972; Oki, Kouno, Kitai \& Ozaki, I972; Hazeu, de Bruyn \& Bos, 1972; Levine \& Cooney, 1973). The yeasts belonged to the genera Kloeckera, Torulopsis, Candida, Pichia and Hansenula.

We have isolated 36 different strains of Candida boidinii and Pichia pinus from more than 600 enrichment cultures prepared during a survey of conditions leading to the enrichment of methanol-assimilating yeasts.

\section{METHODS}

Media. These contained (per litre deionized water): $\left(\mathrm{NH}_{4}\right)_{2} \mathrm{SO}_{4}, 0.5 \mathrm{~g} ; \mathrm{MgSO}_{4} \cdot 7 \mathrm{H}_{2} \mathrm{O}$, $0.2 \mathrm{~g} ; \mathrm{KH}_{2} \mathrm{PO}_{4}, 3.0 \mathrm{~g}$, and $0.2 \mathrm{ml}$ of a trace element solution (Vishniac \& Santer, 1957). The preferred enrichment medium contained in addition (per litre deionized water): vitamin mixture (Ogata, Nishikawa, Ohsugi \& Tochikura, 1970), Io ml; sodium penicillin G (Mycofarm, Delft, The Netherlands), $10^{6}$ units; D-cycloserine (Sigma), $600 \mathrm{mg}$; and methanol, $5 \mathrm{ml}$. The $\mathrm{pH}$ was adjusted to 4.5 with $\mathrm{NaOH}$. The medium was used without sterilization. The utilization of methanol by the isolated yeast strains was studied in the above solution at $\mathrm{pH} 5.5$ in the absence of the antibiotics. In that case the vitamin mixture and methanol were filter-sterilized and added to the mineral medium which had been sterilized at $15 \mathrm{lb} / \mathrm{in}^{2}$ for $15 \mathrm{~min}$ and cooled.

Organisms. The following yeasts were obtained from the Centraal Bureau voor Schimmelcultures, Yeast Division, Delft, The Netherlands: Hansenula capsulata CBSI993, H. nonfermentans CBS5764, $H$. polymorpha CBS4732, H. wickerhamii CBS4307, H. henricii CBS5765, H. glycozyma CBS5766, H. minuta CBSI 708, Pichia pastoris CBS704, P. pinus CBS5098, P. trehalophila CBS536I, Candida boidinii CBS2429.

These organisms were maintained on I \% Difco Malt agar and subcultured twice a year. Slopes were incubated overnight at $28{ }^{\circ} \mathrm{C}$ (except for $H$. polymorpha which was incubated at $37^{\circ} \mathrm{C}$ ) and then stored at $4{ }^{\circ} \mathrm{C}$.

Enrichment and isolation. Conical flasks ( $100 \mathrm{ml}$ ) containing $30 \mathrm{ml}$ of enrichment medium were inoculated with approximately I $g$ of samples taken from soil, rotten wood, leaves, flowers and fruit. The flasks were put on a shaker (Model G25, New Brunswick Scientific Co.) at 28 or $37^{\circ} \mathrm{C}$. They were examined microscopically at 2-day intervals for 3 weeks. In positive enrichments growth of yeasts generally started after 5 to 8 days and after 10 days the cultures were transferred to another flask containing the enrichment medium. Growth 
Table I. Optimal conditions for the isolation of methanol-assimilating yeasts

Factors influencing enrichment

$\mathrm{pH}$ of the medium

Antibiotics

Vitamin mixture

Methanol concentration

Nature of the inoculum
Optimum conditions

4.5 (optimum pH for growth of yeasts on methanol is $5 \cdot 0$ to $6 \cdot 0$ )

Required in the physiological range of $\mathrm{pH}$ values for growth

Necessary since most methanol-assimilating yeasts require one or more vitamins*

0.1 to $0.5 \%(\mathrm{v} / \mathrm{v})$. At methanol concentrations above $0.5 \%$ inhibition of growth occurred in some species

Soil samples rich in organic matter were good sources

* Biotin and thiamin are especially important.

in the second flask was much faster, and 3 days after the transfer samples of the culture were plated on a modified enrichment medium without antibiotics, at $\mathrm{pH} 5.5$, containing $20 \mathrm{~g}$ Difco Bacto-agar/l. Pure cultures of the yeasts were obtained by means of conventional techniques.

Criteria for methanol utilization. A $100 \mathrm{ml}$ conical flask, containing $30 \mathrm{ml}$ of the mineral salts medium + vitamins and supplemented with $0 \cdot 2 \%(\mathrm{w} / \mathrm{v})$ glycerol, was inoculated from a $48 \mathrm{~h}$ old slope and incubated on a shaker at $28^{\circ} \mathrm{C}\left(37^{\circ} \mathrm{C}\right.$ for $\mathrm{H}$. polymorpha $)$. When growth was apparent, $0.2 \mathrm{ml}$ of the culture was transferred to another flask containing $30 \mathrm{ml}$ of the modified enrichment medium at $\mathrm{pH} 5.5$, containing $0.2 \%(\mathrm{w} / \mathrm{v})$ glycerol and $0.5 \%(\mathrm{v} / \mathrm{v})$ methanol. After $48 \mathrm{~h}$ of incubation, $0.2 \mathrm{ml}$ of the culture was transferred to a similar solution containing only methanol as the carbon source. When after five subcultures in the latter medium growth was visible within $72 \mathrm{~h}$, the yeast under study was considered to assimilate methanol.

Identification of the isolated yeasts. This was done by standard methods (Lodder, 1970).

\section{RESULTS AND DISCUSSION}

Preliminary work showed that at $\mathrm{pH} 4.5$ penicillin $\mathrm{G}$ and D-cycloserine virtually prevented bacterial growth in the enrichment cultures. Yeasts were obtained from 15 to $25 \%$ of these.

Of 36 strains eventually isolated in pure culture, 26 were identified as $P$. pinus, and Io as C. boidinii. Only $C$. boidinii was isolated when $\left(\mathrm{NH}_{4}\right)_{2} \mathrm{SO}_{4}$ was replaced by $0.065 \%(\mathrm{w} / \mathrm{v})$ $\mathrm{KNO}_{3}$ as the nitrogen source. Pichia pinus is unable to use nitrate as a nitrogen source for growth (Lodder, 1970). The enrichments were particularly successful when soil, rich in organic matter, from a tropical greenhouse was used as the inoculum. It is notable that when the incubation temperature during the enrichments was $37^{\circ} \mathrm{C}$ no yeasts were isolated. A thermo-tolerant Hansenula strain has been isolated, however, by Levine \& Cooney (1973) and $H$. polymorpha CBS4732 utilized methanol at $37^{\circ} \mathrm{C}$ in our experiments. The optimal conditions for the isolation of methanol-assimilating yeasts are summarized in Table $\mathrm{I}$.

A number of yeast species taxonomically related to our isolates were obtained from the Delft collection. From the genera Pichia and Hansenula all the available type species were tested, whereas from the genus Candida only those species resembling $C$. boidinii were considered. By using the criteria outlined above the following species were found to grow with methanol as the sole source of carbon and energy: H.capsulata, $H$. nonfermentans, $H$. polymorpha, $H$. wickerhamii, $H$. henricii, $P$. pastoris, $P$. pinus, $P$. trehalophila and $C$. boidinii. In contrast to the results reported by Hazeu et al. (1972), H. glycozyma and H. minuta 
failed to utilize methanol. This discrepancy may be due to the use of different criteria for methanol utilization.

All methanol-assimilating yeasts tested so far are unable to grow in batch or continuous culture with the following one-carbon compounds: methane, methylamine, formaldehyde and formate. The results obtained so far indicate that the utilization of organic $C_{1}$ compounds is not widespread among yeasts and is less common than among procaryotic organisms (Quayle, I972).

We are indebted to Dr N. J. W. Kreger van Rij for the identification of our isolates and for her most valuable suggestions for the screening of yeast strains. One of us (J.P.v.D.) was supported by a grant from Shell Research Ltd, Sittingbourne, Kent.

\section{REFERENCES}

Asthana, H., Humphrey, A. E. \& Moritz, V. (1971). Growth of yeast on methanol as the sole carbon substrate. Biotechnology and Bioengineering 13, 923-928.

Hazeu, W., De Bruyn, J. C. \& Bos, P. (1972). Methanol assimilation by yeasts. Archiv für Mikrobiologie $87,185-188$.

LEVINE, D. W. \& COONEY, C. L. (1973). Isolation and characterization of a thermotolerant methanol-utilizing yeast. Applied Microbiology 26, 982-990.

LodDer, J. (1970). The Yeasts. Amsterdam: North-Holland Publishing.

Ogata, K., Nishikawa, H. \& Ohsugi, M. (1969). A yeast capable of utilizing methanol. Agricultural and Biological Chemistry 33, I519-1520.

Ogata, K., Nishikawa, H., Ohsugi, M. \& Tochikura, T. (1970). Studies on the production of yeast. I. A yeast utilizing methanol as a sole carbon source. Journal of Fermentation Technology 48, 389-396.

OKI, T., Kouno, K., KITAI, A. \& OZAKI, A. (1972). New yeasts capable of assimilating methanol. Journal of General and Applied Microbiology 18, 295-305.

QUAYLE, J. R. (1972). The metabolism of one-carbon compounds by micro-organisms. Advances in Microbial Physiology 7, 119-203.

SAHM, H. \& WAGNER, F. (1972). Microbial assimilation of methanol. Isolation and characterization of the yeast Candida boidinii. Archiv für Mikrobiologie 84, 29-42.

Vishniac, W. \& SANTER, M. (1957). The thiobacilli. Bacteriological Reviews 21, 195-213. 